\title{
Determinación de Coliformes Totales y Escherichia Coli en el Estuario Chulluype del Cantón Santa Elena Provincia de Santa Elena
}

\section{Determination of Total Coliforms and Escheichia Coli in the Estuary Chulluype of the Canton Santa Elena, Province of Santa Elena}

Ariana Plúas-Chiquito ${ }^{1}$, Mireya Pozo-Cajas ${ }^{1}$, Christian Lajones-Tapia ${ }^{1}$, Henry Carreño-Rosario ${ }^{1}$, Olga Arévalo-Castro ${ }^{1}$

INFORMACIÓN DEL

\section{ARTÍCULO}

Fecha de recepción: 8 de noviembre de 2019.

Fecha de aceptación: 18 de agosto de 2020

\footnotetext{
${ }^{l}$ Magíster en Relaciones Internacionales, Universidad Central del Ecuador. Becaria del Programa de Doctorado en Estudios Internacionales en la Facultad Latinoamericana de Ciencias Sociales. E-mail: xxx@yahoo.es

Código ORCID:

https://orcid.org/0000-0002-1990-xxxx
}

CITACIÓN: Plúas-Chiquito, A., et al. (2020). Determinación de Coliformes Totales y Escherichia Coli en el Estuario Chulluype del Cantón Santa Elena Provincia de Santa Elena Investigatio, 14, 61-70 doi:10.31095/investigatio.2020.14.6

\section{ENLACE DOI:}

http://dx.doi.org/10.31095/investigatio. 2020.14.6

\begin{abstract}
Resumen
En la actualidad uno de los principales medios de vida está siendo alterado y se debe mayormente por el ser humano, el cual con sus actividades productivas diarias generan las bacterias, que alteran las condiciones físico-químicas del agua. El objetivo del presente trabajo fue determinar la concentración de Coliformes totales y Escherichia coli en el estuario de Chulluype, en la provincia de Santa Elena. Se realizó la recolección y transporte de cinco muestras colectadas aleatoriamente en diferentes puntos del estuario. Se determinó los niveles de concentración de microorganismos y los resultados se compararon con los límites máximos permisibles establecidos en el Anexo 1 Del libro VI del Texto Unificado de Legislación Secundaria del Ministerio del Ambiente (TULSMA). Se obtuvieron valores máximos de Coliformes totales de 4x107 NMP/mL, que sobrepasaron los límites permisibles. Con relación a $E$. coli se obtuvieron valores $2 \times 102 \mathrm{UFC} / \mathrm{mL}$ y no superaron los límites permisibles. Finalmente se propuso una fitorremediación, para recuperar las condiciones naturales del lugar.

\section{Palabras Clave:}

Coliformes, Escherichia coli, estuario, contaminación, bacterias, nivel. Clasificación JEL: JQ29.
\end{abstract}

\begin{abstract}
At the present time, one of the main life means is being altered; this is due mainly to humans, whose productive daily activities generate bacteria that alter physical and chemical water conditions. The present work's aim was to ascertain the total coliforms and Escherichia coli concentration in the Chulluype estuary, in the province of Santa Elena. Five sample were randomly collected in different estuary points. The microorganism concentration levels were ascertained; results were then compared with the maximum permissible limits established in the Ministry of Environment's annex 1 of Book VI of Secondary Legislation Unified Text (TULSMA according to Spanish initials). Maximum total coliform values of $4 \times 107 \mathrm{NMP} / \mathrm{mL}$ were obtained; these exceeded permissible limits. Values of $2 \times 102 \mathrm{CFU} / \mathrm{mL}$ were obtained in relation to $E$. coli and these did not exceed permissible limits. A phytoremediation was finally proposed in order to recover natural conditions.
\end{abstract}

\section{Keywords:}

Coliforms, Escherichia coli, estuary, pollution, bacterium, level.

JEL Classification: JQ29. 


\section{Introducción}

El incremento exponencial de la demografía a nivel mundial ha generado un incremento en la contaminación del recurso hídrico (Goméz-Moreno, Cárdenas-Guzmán, Fuccz-Gamboa, \& Campos, 2007). La contaminación del agua se puede manejar a través del tratamiento de aguas, el cual garantizará que las aguas servidas, usadas por el humano, serán libres de altas concentraciones de (Goméz-Moreno, Cárdenas-Guzmán, Fuccz-Gamboa, \& Campos, 2007).

Los estuarios son ecosistemas costeros especialmente vulnerables a los efectos del cambio climático $\mathrm{y}$ al desarrollo urbano. Al tener un alto valor ecológico, económico y social, forma parte de los objetivos prioritario en las estrategias de conservación y restauración (Uribe \& Urrego, 2009).

Chulluype es una pequeña comunidad que se localiza en la franja costera que delimita la bahía de la parroquia de Santa Elena perteneciente al cantón Santa Elena, provincia de Santa Elena, con coordenadas aproximadas: $2^{\circ} 12^{\prime} 26.51$ " S de latitud y $80^{\circ} 52^{\prime} 37.56^{\prime \prime} \mathrm{O}$ de longitud. Sus límites son: al Norte con el Océano Pacífico, al Este con Ballenita, al Sur con Brisas de Ballenita, y al Oeste con Cautivo (Bastidas, 2011).Chulluype, que es un cuerpo de agua semidulce que se encuentra localizado en la comunidad del mismo nombre, que tiene desembocadura directa con el mar de la localidad. La playa de este lugar está en una pequeña bahía entre bajos acantilados. Y que posee una pronunciada pendiente y zonas rocas.

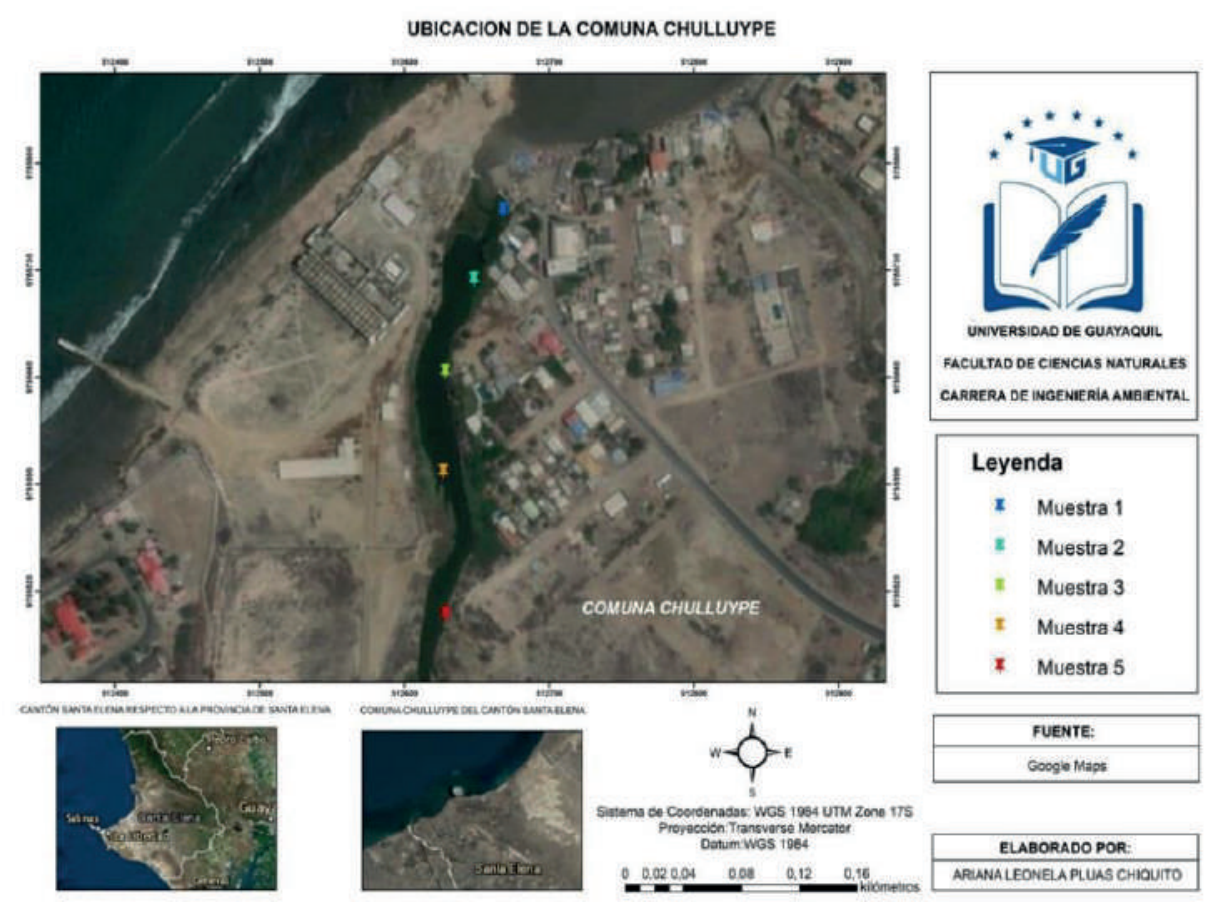

Figura 1. Ubicación geográfica y vista satelital de Chulluype.

Fuente: Elaboración propia. 
El objetivo del presente trabajo fue determinar la concentración de Coliformes totales y de Escherichia coli en el estuario Chulluype en el Cantón de Santa Elena Provincia de Santa ElenaEcuador.

Como hipótesis se considera que existe presencia de Coliformes Totales y Escherichia coli en el estuario Chulluype del cantón Santa Elena provincia de Santa Elena a consecuencia de las actividades antropogénicas de población del sector.

\section{Materiales y métodos}

Para el desarrollo de la investigación se realizó un análisis con 5 muestras aleatorias colectadas en toda la longitud del estuario. Las muestras fueron recolectadas en dos períodos: en marea baja y en marea alta con el fin de relacionar la influencia de las mareas con el incremento de la contaminación.

Los respectivos análisis se realizaron en el laboratorio de Microbiología del (IIRN) de la Facultad de Ciencias Naturales que brindó sus instalaciones y equipos para todo el proceso.

Un día previo al estudio se prepararon 85 tubos de ensayo con agar de enriquecimiento no selectivo de bacterias (agua de peptona). Este agar permite la proliferación de bacterias en un período entre 18 a 24 horas. Se agregó $9 \mathrm{~mm}$ de solución del compuesto formador del agar en cada tubo por medio de una pipeta volumétrica de $10 \mathrm{~mm}$. Después pasó por la autoclave para su respectiva esterilización a 15 psi en baño maría. Una vez esterilizado el agar, se mantuvo a los tubos de muestras bajo luz UV en una cámara de flujo laminar para mantener la esterilidad.

Para la detección de coliformes y diferenciación de E.coli presentes en agua, en un período de 24 horas, se utilizó el agar chromocult, el cual es un reactivo cromógeno diferencial, que a través de la B-D-galactosidasa, una enzima que es distintiva de las bacterias coliformes, se genera la división del sustrato Salmon-GAL, por este suceso se obtienen colonias con una tonalidad rojo asalmonado (MERCK, 2014).

Para el sembrado de muestras se utilizó cajas Petri previamente rotuladas, se procedió a llenar los tubos con las muestras y sus duplicados; como siguiente paso se efectuó las diluciones de cada duplicado procurando homogenizar la muestra y el agar para evitar alteraciones en los resultados, se hizo hasta la 5ta dilución en secuencias sucesivas de 1/10-1,1/10-2,1/10-3, $1 / 10-4,1 / 10-5$ y se tomó como referencia la técnica ISO 9308-1 que indica como es la descarga en cada placa con el fin de determinar hasta qué fase estaba contaminada. En el siguiente proceso se efectuó la siembra de muestras en las cajas Petri, se vertió $1 \mathrm{ml}$ de la solución en los tubos y se vertió $15 \mathrm{ml}$ de agar Chromocult Delgado (2018), se homogenizó moviendo cada Petri en forma de "S" para mejores resultados.

Todo el suceso se efectuó en la cámara de flujo laminar, durante las diluciones y 
sembrado de muestras se usaron micropipetas y puntas previamente esterilizadas de $1 \mathrm{~mL}$.

Se realizó un análisis de correlación para diagnosticar el principal factor de contaminación, también se valoraron otros parámetros de calidad como son: $\mathrm{pH}$, temperatura, salinidad y conductividad para determinar la calidad del agua con el fin de describir en qué estándares está el área de estudio y la influencia de éstos con la proliferación y crecimiento de bacterias en el lugar y su afectación a la sociedad aledaña.

El análisis del $\mathrm{pH}$ (potencial de hidrógeno) fue tomado ex situ y se la realizó en el laboratorio IIRN y se utilizó un phímetro calibrado, se lo introdujo en cada muestra, para evitar alteración en resultados entre cada análisis se neutralizaba el $\mathrm{pH}$ con agua destilada.

Para el análisis de salinidad se implementó un Refractómetro para contenido de sal PCE-0100, el cual funciona al colocar una gota de la muestra en el prisma ubicado en la parte delantera de la herramienta y a través de una escala óptica de 0 a 100 obtener resultados de manera rápida (PCE-IBÉRICA, 2017).

La escala de la temperatura fue tomada in situ para conocer las condiciones del área de estudio, para este proceso se usó un termómetro de mercurio.

Se utilizó la prueba de Anderson Darling y la prueba de Shapiro para determinar si los valores presentaban una distribución específica o si los datos provienen de una distribución normal. Para los análisis de presencia de bacterias se implementó la prueba no paramétrica de Kruskal Wallis $(\mathrm{p}<00,5)$, debido a que los datos no tenían una distribución normal (Delgado, 2018).

Con los parámetros fisicoquímicos obtenidos del estudio se procedió a realizar un análisis en base a la prueba estadística de Rangos de Spearman Rho que, según Evans, (1996), estableció una guía para para medir la fuerza de la correlación entre rangos comparativos absolutos.

\section{Resultados}

Una vez realizado los respectivos análisis en el laboratorio, el conteo de colonias y evaluado los diferentes parámetros tanto físicos como químico se obtuvo los siguientes resultados:

La variabilidad de coliformes totales entre las cinco muestras se evidenció tanto en marea alta como en marea baja. Adicionalmente, los valores de coliformes totales superaron el rango permisible estipulado por la normativa, de acuerdo al criterio de calidad de aguas para fines recreativos mediante contacto secundario dispuesto por el TULSMA Libro VI anexo 1 (4x103NMP/mL). Sin embargo, la muestra 1 no sobrepasa los límites permisibles en marea baja y marea alta con (2x103 UFC/mL). Así mismo se estableció que en el promedio de las muestras no se detectaron diferencias estadísticamente significativas entre el 
ciclo de mareas, ya que en ambas se registra la presencia de actividad microbiana, siendo en la marea baja donde se concentra la mayor cantidad de coliformes totales $(\mathrm{KW}=4$; $\mathrm{p}=0.406)$.
Se determinó presencia de E. coli únicamente en la muestra 1 en marea baja con $2 \times 102 \mathrm{UFC} / \mathrm{mL}$, valor que no sobrepasa el límite máximo permisible dispuesto por criterio de calidad de aguas

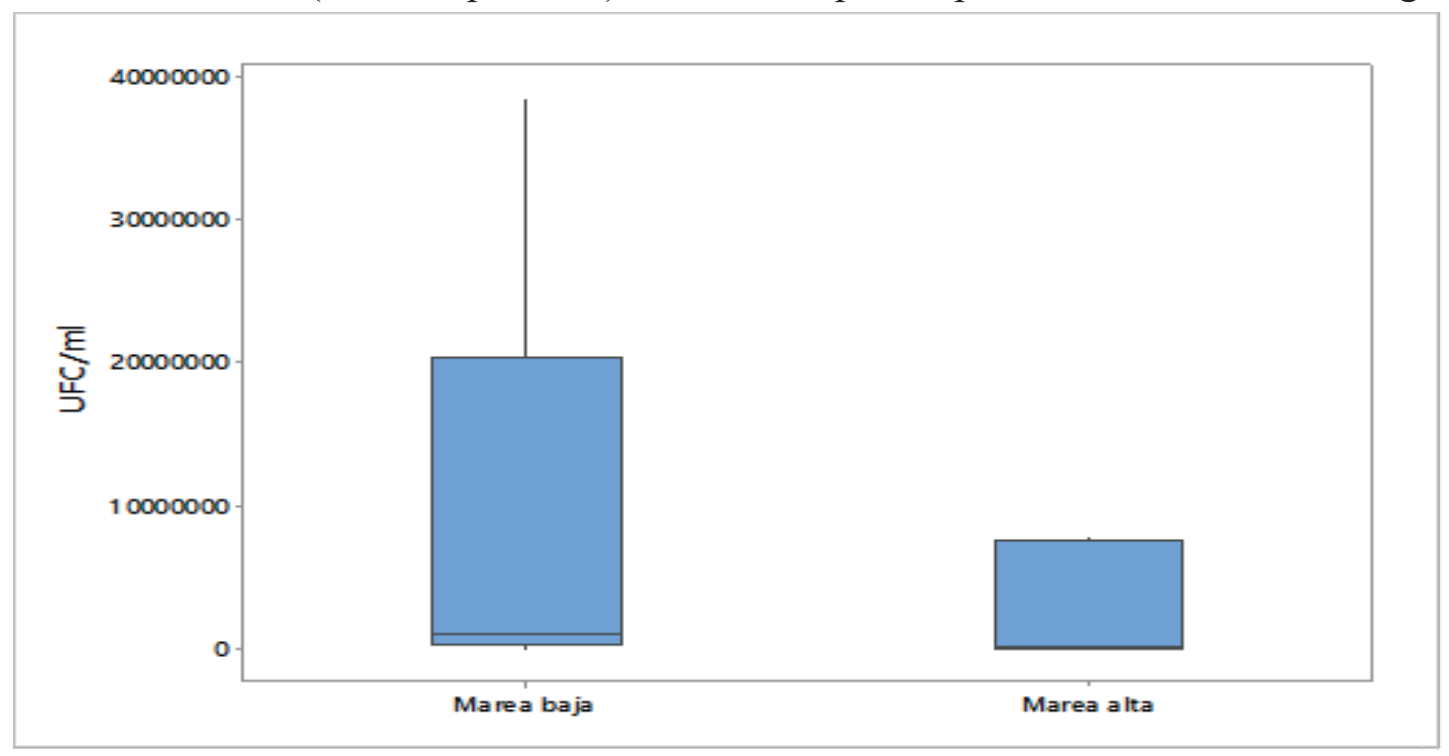

Figura 2. Concentración de Coliformes totales en Marea baja y Marea alta, representado por Boxplot en base a la prueba de Kruskal Wallis.

Fuente: Elaboración propia.

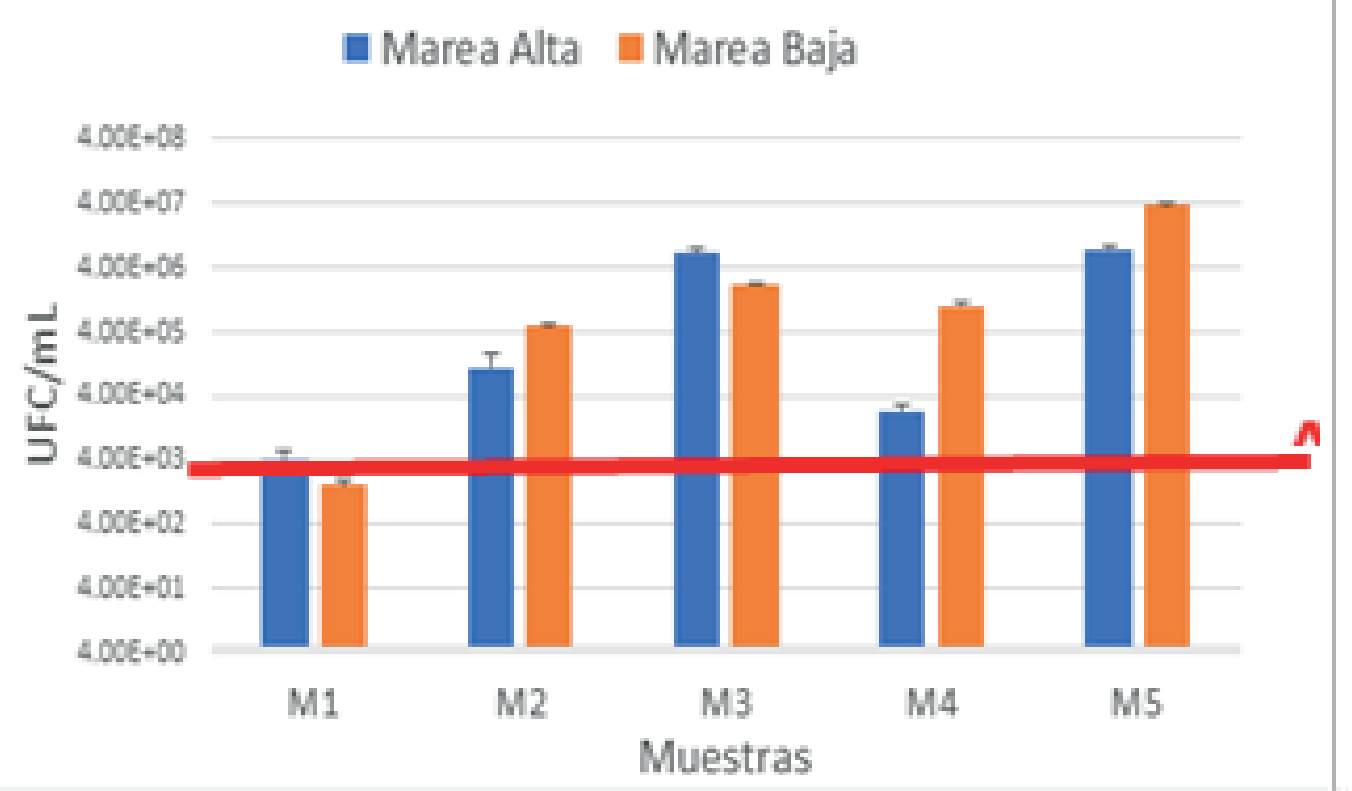

Figura 3. Concentración de Coliformes totales en diferentes puntos (M1, M2, M3, M4, M5) del estuario de Chulluype en el cantón de Santa Elena. A. Límite máximo permisible según la normativa nacional TULSMA Libro VI Anexo 1 (4x103 NMP/mL). Las barras representan la media \pm error estándar.

Fuente: Elaboración propia. 
para fines recreativos mediante contacto secundario dispuesto por el TULSMA Libro VI anexo 1 (1x103NMP/mL).

Para la correlación de los valores fisicoquímicos, en marea baja se evidenció que las variables ambientales de $\mathrm{pH}$ y temperatura en el estudio presentaron una correlación negativa con rangos entre $-0,4$ y -0.45 respectivamente, en tanto la variable de salinidad y salinidad poseen un rango positivos entre 0,5 y 0,48 (Tabla 1 ). Esto indica que en marea baja a menor $\mathrm{pH}$ mayor concentración de coliformes totales y en marea alta es lo contrario, a mayor $\mathrm{pH}$ mayor concentración de $E$. coli, en el caso de la Salinidad y Conductividad, a mayor salinidad y conductividad mayor concentración de coliformes. Sin embargo, los valores de correlación en general son bajos-intermedios, lo cual indica que las concentraciones de coliformes totales, parecen no depender en gran proporcion de las variables ambientales en las zonas de marea baja y alta y que existen otras variables que puedan estar determinando su presencia, mas allá del pH, Salinidad, conductividad y temperatura. Más bien debido a las condiciones del sistema semi-cerrado y a la acumulación de sedimentos contaminados generan el incremento de la actividad microbiana al existir fuentes de descargas directas que alteran el estuario de Chulluype. Es importante mencionar que en la fase de marea altaexiste una dilución y dispersión de coliformes totales al existir mayor fricción con el oleaje.

Tabla 1.

Correlación de parámetros fisicoquímicos con la abundancia de coliformes totales

\begin{tabular}{ccccc}
\hline & $\mathrm{pH}$ & \multicolumn{3}{c}{ Salinidad } \\
\hline $\begin{array}{c}\text { C.T } \\
\text { Marea Baja }\end{array}$ & $-0,40$ & 0,50 & 0,48 & $-0,45$ \\
$\begin{array}{c}\text { C.T } \\
\text { Marea Alta }\end{array}$ & 0,47 & 0,50 & 0,48 & $-0,39$ \\
\hline
\end{tabular}

Fuente: Elaboración propia.

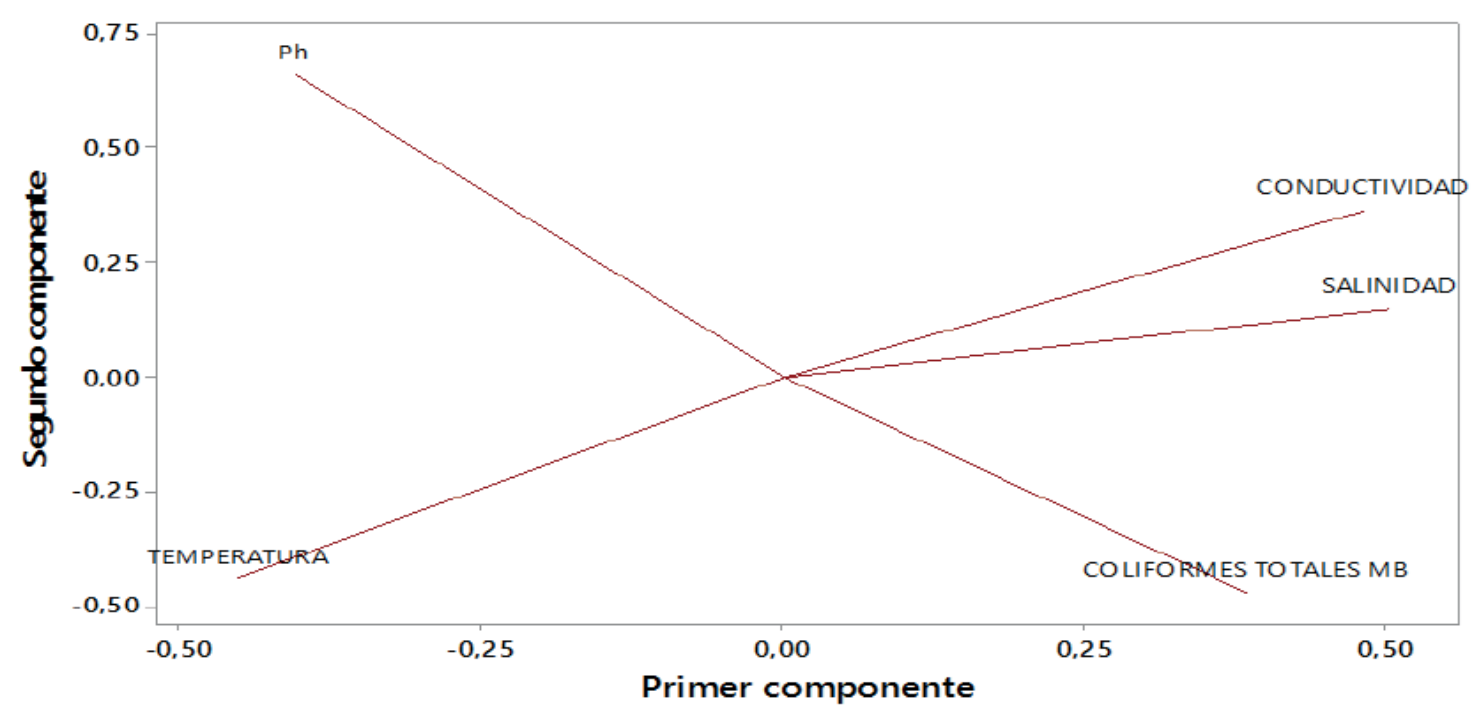

Figura 4. Análisis de Componentes Principales (ACP) de Coliformes Totales en Marea Baja y los parámetros fisicoquímicos: pH, temperatura, salinidad y conductividad.

Fuente: Elaboración propia. 
Se hizo un de Análisis de Componentes principales con la finalidad de demostrar la relación entre los resultados de coliformes totales marea baja y marea alta y los parámetros fisicoquímicos ( $\mathrm{pH}$, salinidad, conductividad y temperatura), evidenciando qué: los valores de coliformes tanto en marea baja como en marea alta presentan una influencia positiva directa con el $\mathrm{pH}$ y no existe influencia por con los otros parámetros (Figura 4).

\section{Discusión}

Los estuarios aportan un sin fin de beneficios a la comunidad aledaña a su ubicación, debido a que es una zona de transición entre ríos y el mar, tiene interacción entre ambas condiciones, esto los hace muy productivos, con mucha variedad de hábitats, albergando gran cantidad y diversidad de especies, brindando muchos servicios ecosistémicos.
El estuario Chulluype posee una influencia directa de las aguas residuales de las poblaciones que están en la zona de influencia, lo que conlleva a que sea intervenido, dando como resultado la presencia de altas concentraciones de Coliformes totales y E. coli (Gavilanes, Jalón, Magües, \& Delgado, 2009). Lo cual se comprobó en este estudio, ya que se reportó la presencia de coliformes fecales y E. coli en las aguas muestreadas del estuario.

De acuerdo a los análisis de las concentraciones de Coliformes totales en Marea Baja y Marea Alta oscilan entre $1,6 \times 103$ hasta $3,8 \times 107 \mathrm{UFC} / \mathrm{mL}$ lo que nos evidencia la contaminación fecal en el estuario estudiado. De acuerdo con el Texto Unificado de legislación Ambiental el límite máximo permisible de Coliformes Totales es de 4x103 $\mathrm{NMP} / \mathrm{mL}$; por lo cual podemos determinar que de acuerdo a la normativa nacional vigente de aguas para fines

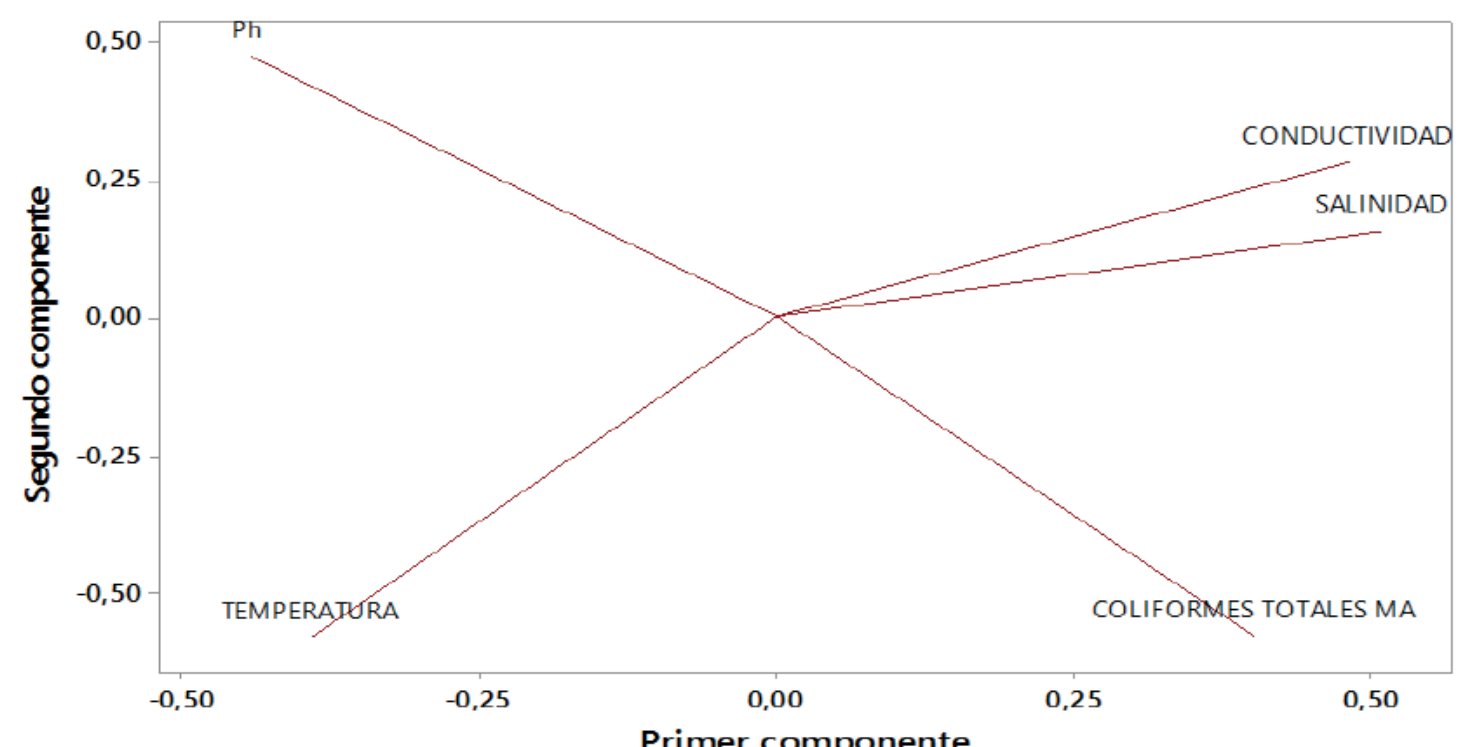

Figura 5. Análisis de Componentes Principales (ACP) de Coliformes Totales en Marea Alta y los parámetros físicoquímicos: pH, temperatura, salinidad y conductividad.

Fuente: Elaboración propia. 
recreativos no es apto, debido a las características geomorfológica del filo costero en el área de estudio la boca del estuario Chulluype desemboca en la mar por lo tanto estas aguas tienen una influencia directa a la zona de la playa donde es una área de turismo nacional e internacional por lo tanto puede ocasionar enfermedades gastrointestinales a locales y extraños.

Los muestreos realizados de coliformes totales en nuestra área de estudio $(3,8 \times 107 \mathrm{UFC} / \mathrm{mL})$ está por debajo de los encontrado en el estero salado en Guayaquil, Ecuador por Baños (2012), obteniendo valores de 84 $\mathrm{UFC} / \mathrm{mL}$ a $7 \times 103 \mathrm{UFC} / \mathrm{mL}$ para coliformes Totales; en lo que respecta a E. coli obtuvieron valores sumamente altos de $1,8 \mathrm{UFC} / \mathrm{mL}$ a $1,8 \times 102 \mathrm{UFC} / \mathrm{mL}$ en comparación a los obtenidos en nuestro estudio los cuales fueron nulos en casi todos los puntos de muestreo a excepción de punto M1 en el que se obtuvo 1,6x101 UFC/mL en marea baja lo que corrobora que no existe presencia de material fecal al en el periodo de muestreo.

Al analizar los datos obtenidos en la correlación de los parámetros fisicoquímicos con los niveles de concentración de coliformes totales en marea baja y alta no se observaron relación entre ellas los que se verifica en el estudio realizado en el Rio Yaguachi por Valencia (2018), confirma que la contaminación es antropogénica y no varía por el $\mathrm{pH}, \mathrm{DBO}, \mathrm{DQO}$, Salinidad y presume que las aguas del Rio Yaguachi se encuentran contaminadas con coliformes totales $\mathrm{y}$ fecales por la constante descarga de aguas residuales a lo largo de la rivera del rio, cuyo mismo problema posee el estuario Chulluype.

Las casas en la zona de influencia directa e indirecta del área en estudio no tienen planta de tratamiento de aguas residuales tiene "pozos ciegos" que desconocemos si estas aguas se están filtrado por motivos naturales o por la pendiente hacia el estuario por lo tanto ayudan a la contaminación del área.

Los servicios ecosistémicos que nos brindan las lagunas costeras-estuarinas no son entendidos por los tomadores de decisiones en el momento de autorizar cualquier actividad económica en la zona de influencia y trae como consecuencia la contaminación de las aguas del estuario y la perdida de hábitat que sirven de refugio de especies marítimas migratorias que una etapa de desarrollo de las misma necesita estos tipos de ecosistemas

Debido a que el estuario Chulluype es un cuerpo de agua semicerrado que está influenciado por la marea, la falta de diferencias significativas en las lecturas de los parámetros físicos químicos entre marea baja y alta puede deberse a que las mediciones se realizaron época seca. Las características de una laguna costeraestuarina cambian de acuerdo a cada época de lluvia y seca (Gavilanes, Jalón, Magües, \& Delgado, 2009), por lo que es necesario realizar investigación para entender la dinámica del área y determinar en qué estación este ecosistema es más afectado por la contaminación. 


\section{Conclusiones}

Con bases en los resultados obtenidos en los análisis del presente estudio se confirma la hipótesis sobre la presencia de Coliformes Totales y Escherichia coli en el estuario Chulluype del cantón Santa Elena provincia de Santa Elena a consecuencia de las actividades antropogénicas de población del sector.

Además, se identificaron valores de Coliformes totales de hasta $4 \times 107$ $\mathrm{UFC} / \mathrm{mL}$ en marea baja y $8 \times 107 \mathrm{UFC} / \mathrm{mL}$ en marea Alta. Comprobando que el Punto M5 el punto mayormente influenciado por las descargas al estuario en comparación a los otros puntos de muestreo, tanto en Coliformes totales en los cinco puntos de muestreo en el estuario de Chulluype en el Cantón de Santa Elena.

Por otro lado, se superan los límites máximo permisibles de coliformes totales en todos los puntos de muestreo a excepción del punto M1 en marea baja; en lo que respecta a E. coli en ninguno de los puntos de muestreo se superaron los Límites Máximos Permisibles (LMP). Esto último, indica que las descargas que recibe el estuario Chulluype tienen menor cantidad de E. coli que de Coliformes fecales.

El bajo conteo de colonias de E. coli en los puntos de muestreo demuestran concluyen que no influye la presencia de material fecal en el estuario Chulluype

En conclusión, se sugiere garantizar la buena calidad del recurso hídrico y un mayor control de las aguas residuales que se vierten en estuario como lo establece la normativa legal vigente y se propone implementar un sistema de fitorremediación combinando las propiedades de la Lemna minor (Lenteja de agua) y Salvinia auriculata (Salvinia) en los reservorios y Scirpusholos choenus (Junco de Agua) y Schoenoplectus californicus (Totora) en el cauce del estuario Chulluype ; de igual forma se propone un mayor control de las descargas que generan la comunidades aledañas.

Sería conveniente realizar monitoreos de coliformes totales, E. coli y de otros parámetros con mayor periodicidad tanto en marea alta y marea baja a lo largo del estuario Chulluype y difundir la propuesta elaborada en este estudio al organismo pertinente para su implementación en el estuario Chulluype y en otros cuerpos hídricos con características semejantes; con el fin de evitar que sea considerado un punto crítico de contaminación.

Se recomienda identificar otras fuentes de contaminación, cuyas actividades no se encuentren reguladas y arrojen sus vertidos al estuario sin previo tratamiento y seguir realizando proyectos de investigación en este Ecosistema Estuarino debido que en el Ecuador han desparecidos por el cambio de uso de suelo.

\section{Referencias}
Bastidas, G. (2011). Propuesta de Turisficación en Chulluype Cantón Santa Elena. La Libertad. (Trabajo de Titulación). https://repositorio.upse.edu.ec/xmlui/han dle/46000/2831


Delgado, D. (2018). Niveles de Coliformes totales y Escherichia coli en Anadara tuberculosa y Anadara similis en el Recinto El Morro, Provincia Del Guayas. Guayaquil. (Trabajo de Titulación) http://repositorio.ug.edu.ec/bitstream/red ug/29451/1/Dayana\%20Delgado.pdf

Evans, J. (1996). Evans, JD (1996). Straight forward statistics for the Behavioral Sciences. Brooks / Cole, Publishing Pacific Grove, California. California: Publishing Pacific Grove.

Gavilanes, J., Jalón , V., Magües , I., \& Delgado, D. (2009). Propuesta de Equipamiento en el Sector de Chulluype: Cabaña Comedor Turístico. Obtenido de https://www. dspace.espol.edu.ec/bitstream/12345678 9/1687/1/3385.pdf

Goméz-Moreno, R., Cárdenas-Guzmán, M., FucczGamboa, J., \& Campos, P. C. (2007). Comportamiento de coliformes fecales como indicadores bacterianos de contaminación fecal en diferentes mezclas de biosólido y estériles utilizados para la restauración ecológica de la cantera soramata, Bogotá. Universitas Scientiarum, 12 (II) p.111-120.

MERCK. (2014). Chromocult Agar para coliformes: Deteccion simultánea de bacterias coliformes y E.coli en el agua. obtenido $d$

file://C:/Users/USUARIO/Downloads/ DS4485ES00_Chromocult\%20Coliform $\% 20(6-25) \% \overline{2} 0(1)$.pdfwww. merckmillip ore.com/chromocult

PCE-IBÉRICA. (2017). Equipos de medidaBalanzas-Regulación y control. Obtenido de Refractómetro de mano: https:// www.pce-iberica.es/manuales/manual-ref ractometro-2.pdf

Uribe, J., \& Urrego, L. (2009). Gestión Ambiental de los Sistemas de Manglar. Revista Gestión y Ambiente, 12 (2) 57-72
Valencia, R. (2018). Distribución Especial y Temporal de Coliformes Totales $y$ Fecales en el Río Yaguachi. (Trabajo de titulación). Obtenido de: http://repositorio.ug.edu.ec/handle/redug $/ 35182$ 